\title{
SYSTEM DYNAMICS MODEL DEVELOPMENT BY ANALYZING CAUSES OF FUKUSHIMA DAIICHI NPP UNIT-1 ACCIDENT
}

\author{
Muhammed Mufazzal Hossen, Mahmud Hossain \\ Nuclear Power and Energy Division \\ Bangladesh Atomic Energy Commission, Bangladesh
}

\begin{abstract}
Fukushima Daiichi NPP accident occurred on March 11, 2011. A system dynamics model is developed by analyzing the chronological progression and causes of the Fukushima Daiichi NPP unit-1 accident applying causeeffect relationship and qualitative causal loop and feedback loop. The accident progression demonstrates that the safety system of the NPP could not function properly, resulting in the loss of core cooling and confinement of radioactive materials functions, and a severe accident with hydrogen explosion occurred. The system dynamics model shows that earthquake, tsunami induced flooding, design failure of Tsunami height, loss of all AC power, loss of DC power, loss of ultimate heat sink, failure of HPCI system, failure of IC system, design complexity of isolation valves of IC and lack of training on IC operation, delayed water injection to reactor, delayed operation of containment venting, lacking of compressed air, high reactor pressure, and harsh radiological condition are the causes of this severe accident. High reactor pressure and harsh radiological condition were produced during the accident, which positively boost accident progression by demonstrating the effect of system dynamics. The conservative design to protect power sources from natural events and the loss of all power for an extended period must be considered during future design of NPP.
\end{abstract}

Keywords - Accident Progression, Causes, Core Cooling, Fukushima Daiichi NPP unit-1, System Dynamics

\section{INTRODUCTION}

Severe accidents in nuclear power plant (NPP) may be caused due to multiple failures of safety systems, resulting in significant core degradation with the release of radioactive material [1]. Three basic safety functions ensure the safety of NPP are the controlling the reactivity of nuclear fuel, the removing the heat from the reactor, and the confining of the radioactive materials [2]. Fukushima Daiichi NPP unit-1, 2, and 3 were in operation, and unit- 4,5 , and 6 were shut down at the time of the devastating earthquake in Japan on March 11, 2011 [3]. The earthquake and the following tsunami led to the loss of AC and DC power, with multiple failures of safety systems, and a severe accident occurred in all three operating reactors in Fukushima Daiichi $[4,5,6]$. The study to identify the causes for this accident is still on-going. The Fukushima Daiichi NPP unit-1 accident can be investigated by a short review of the chronological progression and the causes of this accident can be analyzed applying system dynamics approach.

System dynamics is a computer simulation modelling technique to frame, understand and discuss complex issues in a complicated system $[7,8]$. It is a qualitative and quantitative tool with causal loop and feedback loop diagrams to develop the inter-relations such as cause-effect relations, non-linear behavior, and dynamic changes for a complex project [9]. In a system dynamics model, casual loop shows inter relations among different causes of a system while feedback loops are closed chains of cause-effect links by which more actions can be generated $[10,11]$. Different causes of NPP accident can be modeled by applying a system dynamics approach.

An investigation of the chronological progression through brief literature review and a systematic analysis to investigate the causes through system dynamics approach of the Fukushima Daiichi NPP unit-1 accident are appropriate. The main objectives of this study are to analyze the chronological progression with the response of the reactor safety systems and operator actions through a brief review, and to find the causes by applying system dynamics methodology for Fukushima Daiichi NPP unit-1 accident. The analysis is covered in this study from the earthquake to the explosion.

The research framework of this study are shown in Figure 1. As shown in Figure 1, the research problem is identified first, which is the investigation of Fukushima Daiichi NPP unit-1 accident. Secondly, the overview of Fukushima Daiichi NPP unit-1 is provided. Thirdly, a chronological accident progression through brief literature review is described in view of the response of the reactor safety systems and operator actions. Fourthly, a system dynamics model is developed by analyzing the chronological progression and causes of this accident by using cause-effect relationship and by applying causal and feedback loop diagram qualitatively. Finally, the study was concluded through describing the importance and signaling future research to ensure the safety of NPP. 


\section{International Journal of Engineering Applied Sciences and Technology, 2021 \\ Vol. 6, Issue 4, ISSN No. 2455-2143, Pages 68-73 \\ Published Online August 2021 in IJEAST (http://www.ijeast.com)}

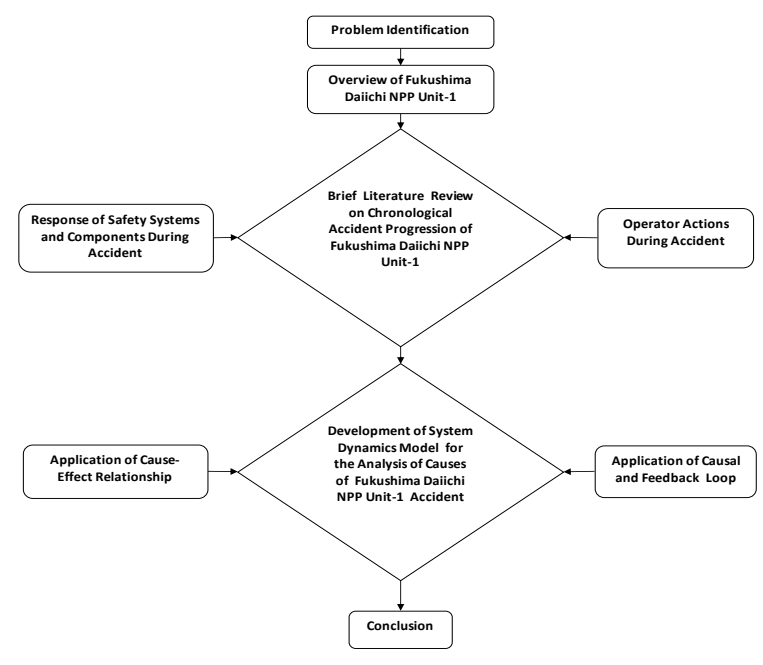

Fig. 1.Research Framework of Analysis of Fukushima Daiichi NPP Unit-1 Accident

\section{LITERATURE REVIEW ON FUKUSHIMA DAIICHI NPP UNIT-1 ACCIDENT}

\section{A. Overview of Fukushima Daiichi NPP Unit-1}

The Fukushima Daiichi NPP site was designed based on the tsunami during Chile's earthquake of magnitude 9.5 on 24 May, 1960 [12] and NPPs were designed for horizontal acceleration as $0.45 \mathrm{~g}$ and vertical acceleration as $0.42 \mathrm{~g}$ [13]. According to the 1966 Establishment Permit of Fukushima Daiichi NPP unit-1, the tsunami height was designed as 3.122 $\mathrm{m}$ above the Onahama Port (OP) level, and the tsunami height was reassessed in 2002 and 2009 as $5.7 \mathrm{~m}$ and $6.1 \mathrm{~m}$ above the OP level respectively, and measures were taken to raise the pump elevation and to make buildings watertight $[3,4]$. The Fukushima Daiichi NPP unit-1, a boiling water reactor with thermal power of $1380 \mathrm{MWth}$ (460 MWe) [13] commissioned on 26 March, 1971[14]. It has two fission barriers as primary containment vessel (PCV) and reactor building (RB), and PCV consists with the drywell (DW) where the reactor is located, and the DW connected to the suppression chamber (SC) [4].

The shutting down objective, the scram is maintained using control rod drive hydraulic pressure systems, and the subcriticality is maintained applying a standby liquid control system in Fukushima Daiichi NPP unit-1 [15]. If the reactor is isolated under high pressure, the isolation condenser (IC), consisting of two closed loops, each containing a heat exchanger outside the containment, four valves with two valves outside the containment operated by DC power and two valves inside the containment operated by $\mathrm{AC}$ power, is used to remove core decay heat [16]. The steam from the reactor enters the IC and the condensed water returns to the reactor by gravity [17]. The high pressure coolant injection (HPCI) is used for reactor injection at high pressure requiring DC power for operation [16]. The core spray system consisting of two trains required $\mathrm{AC}$ power for operation, and the alternative cooling water injection to the reactor as an accident management (AM) measure was implemented at low pressures by make-up water condensate system and fire protection (FP) system with a motor-operated pump and a diesel driven pump [15]. Reactor overpressure protection can be provided by three safety valves, discharged steam to DW and four safety relief valves, discharged to SC and the shutdown cooling system is applied to cool the core, requiring depressurization $0.862 \mathrm{MPa}$ [4]. The confining inside is maintained by PCV cooling and PCV venting, and the PCV cooling is preserved by two trains containment cooling spray (CCS) systems, requiring $\mathrm{AC}$ power for operation [15]. To prevent PCV failure from overpressure, hardened venting was used in Fukushima Daiichi NPP with a rupture disc in the vent line to avoid unintended radioactive release [18], and the PCV can be vented from the SC or DW [16]. The Fukushima Daiichi NPP unit-1 was equipped with two emergency diesel generators (EDGs) to supply AC power, and it can withstand a station blackout (SBO) scenario with the DC batteries of eight hours [3].

\section{B. Progression of Fukushima Daiichi NPP Unit-1 Accident}

The Great East Japan earthquake occurred on March 11, 2011, at 14:46, with a magnitude of 9.0 [19], and the Fukushima Daiichi NPP site sensed horizontal acceleration $0.56 \mathrm{~g}$ and vertical acceleration $0.31 \mathrm{~g}$ [13]. At 14:46:46, automatic scram was triggered, and the reactor was shut down by inserting all control rods at 14:47 [15]. So, the control of the reactivity had been confirmed, but core decay heat must be removed.

The earthquake made the loss of off-site power and the reactor was automatically isolated by the main steam isolation valves closure at 14:47:50, followed by the trip of feed water pumps and water condenser pumps at 14:47:52 and the automatic starting of EDGs at 14:47:57 [15]. At 14:52, both IC automatically started due to high reactor pressure signal as 7.13 $\mathrm{MPa}$, followed by the manual closing of both IC at 15:03 to retain the reactor temperature reduction rate less than 55 ${ }^{\circ} \mathrm{C} /$ hour [3]. Operators manually activated two trains CCS system at 15:05 and 15:11 due to the increase of pressure and temperature of PCV [4]. Operators manually restarted one train of IC at 15:17, 15:24, and 15:32 while stopped at 15:19, 15:26, and 15:34 to regulate the reactor pressure [20]. So, the reactor decay heat was removed by ICs after the earthquake.

The first tsunami wave and the second, the largest tsunami wave reached the site at 15:27, and 15:35 respectively, and the flood height was almost from $11.5 \mathrm{~m}$ to 15.5 above the OP level on Fukushima Daiichi NPP unit-1 [3]. The tsunami submerged seawater pumps, making the loss of the ultimate heat sink and damaged both EDGs [18]. At 15:37, the EDGs were tripped, and the Site Superintendent determined the situation as SBO at 15:42 under Article 10 of the Nuclear Emergency Act and notified the government, and DC power was steadily lost from 15:37 to $15: 50$ due to flooding [4]. The plant status could not be confirmed due to the loss of displays 


\section{International Journal of Engineering Applied Sciences and Technology, 2021 Vol. 6, Issue 4, ISSN No. 2455-2143, Pages 68-73 \\ Published Online August 2021 in IJEAST (http://www.ijeast.com)}

of monitoring instruments and various lamps of MCR and the HPCI was inoperable [15, 21]. At 16:36, Site Superintendent declared the loss of ECCS cooling water injection function according to the Article 15 of the Nuclear Emergency Act, and notified to government at 16:45 but the reactor water level was confirmed as $+2.53 \mathrm{~m}$, above the top of the active fuel (TAF) at 16:42, and the declaration was cancelled at 16:45, followed by the unconfirmed reactor water level at 17:07, thus the Article 15 was declared again and notified to the government at 17:12 $[3,4]$. Thus, the core cooling function was lost.

Meanwhile, DC power was recovered partially and operators opened IC valves outside PCV of one loop at 18:18 and steam generation sounds were confirmed, but stopped soon, and operators closed the return piping isolation valve outside PCV at 18:25 concerning IC shell side water depletion [21]. Operators confirmed the reactor pressure as $6.9 \mathrm{MPa}$ in the RB at 20:07 and the reactor water level as $+0.2 \mathrm{~m}$ above the TAF at 21:19, and the Site Superintendent prohibited entry into the RB at 23:05 due to the increasing radiation level [3].

At 17:12, the Site Superintendent ordered AM measure, reactor injection via FP line, and operators led for field checks at 17:19 and the diesel driven fire pump (DDFP) automatically started at 17:30 due to fault recovery operations, but kept shut down until the FP line completion [3]. The FP line was completed by 20:30, but reactor injection could not perform because of low DDFP discharge head $0.79 \mathrm{MPa}$ compared to high reactor pressure 7.0 $\mathrm{MPa}$. Operators found out DDFP as inoperable at 01:48 on March 12, and the connection to the FP system, using fire engine was completed at 03:30, and fresh water injection into the reactor was started around 04:00 [4], which was briefly stopped due to field radiation level and restarted at 05:46 [3].

At 23:50, DW pressure was measured as $0.6 \mathrm{MPa}$, more than the highest design pressure of $0.528 \mathrm{MPa}$, and the venting plans were approved by the government around $01: 30$ on March 12 , followed by the rise of DW pressure to $0.84 \mathrm{MPa}$ around 02:30, and decreased to $0.8 \mathrm{MPa}$ at 02:45 [4]. The dose rate near the site main gate as $0.069 \mu \mathrm{Sv} / \mathrm{h}$ at $04: 00,0.59 \mu \mathrm{Sv} / \mathrm{h}$ at 04:23, was notified to government at 4:55 [4, 15]. Thus, the confinement of radioactive materials appeared to be degraded.

The legal order for PCV venting was issued by the government orally at 06:50 on March 12, and at 08:03, the Site Superintendent ordered for venting in one hour and the Fukushima Prefecture government was informed at 08:37 that venting would start at 09:00 [4]. At 09:15, the first team opened to $25 \%$ of the motor-operated vent valve of PCV in the $2^{\text {nd }}$ floor of RB according to procedures, and at 09:24, the second team led to the RB basement to open the air-operated valve of the SC vent line, but returned due to the exceeding dose limit of $100 \mathrm{mSv}$, and the third team cancelled work due to high field radiation levels [3]. A temporary air compressor was used for the large SC vent valve opening and venting started at 14:00, steam was visible above the stack and the DW pressure decreased from 14:30 until 14:50 [21].
By 14:53 on March 12, the FP tank for fresh water injection had been depleted, and the preparation of seawater injection to the reactor was completed at 15:30 [4]. At 15:36, a hydrogen explosion occurred in the top side of RB [21], which is considered as the direct sign of core melting [17]. The sea water injection into the reactor started at 19:04 [15].

\section{SYSTEM DYNAMICS MODEL DEVELOPMENT FOR ANALYZING CAUSES OF FUKUSHIMA DAIICHI NPP UNIT-1 ACCIDENT}

Vensim computer software tool, a visual modeling tool [22] is used to develop the qualitative system dynamics model by analyzing the chronological accident progression and causes of the Fukushima Daiichi NPP unit-1 accident. The system dynamics model for the analysis of causes of Fukushima Daiichi NPP unit-1 accident is shown in Figure 2. The positive '+' sign and the negative'-' sign shown in Figure 2 is defined as a positive effect and a negative effect respectively for the incidence of one cause by the effect of another cause to the occurrence of a severe accident with the hydrogen explosion.

The root cause of the Fukushima Daiichi NPP unit-1 accident is the earthquake, which triggered the causes of the accident in two directions, as the loss of off-site AC power and the tsunami induced flooding. The tsunami induced flooding made the failure of the design basis Tsunami height. The flood damaged the cooling seawater pumps and motors, making the loss of the ultimate heat sink. It also damaged the EDGs, making the loss of on-site AC power, and inundated the on-site DC batteries and power panels, making DC power loss. So, the failure of the Tsunami height triggered the causes in three directions as the loss of the ultimate heat sink, the on-site AC power loss, and DC power loss of the Fukushima Daiichi NPP unit-1.

The loss of all AC power and DC power made the failure of ECCS. The HPCI was inoperable due to DC power loss. The IC system, which removes decay heat from the reactor, failed due to the AC power loss, the DC power loss, and the design complexity of isolation valves of ICs and the lack of training on IC operation. The fresh water injection to the reactor as the AM by using the FP system through DDFP was delayed due to high reactor pressure and ultimately failed, and station fire engines used for fresh water injection. The high reactor pressure, low discharge head of DDFP, harsh radiological condition, and the failure of DDFP were the causes for delayed fresh water injection. Thus, the use of the fire engine had a negative influence on the delayed fresh water injection to the reactor, as shown by the '-' sign in Figure 2. Due to the failure of the ultimate heat sink, HPCI, IC, and the delayed fresh water injection to the reactor, the loss of the core cooling occurred.

The reactor pressure raised due to the core cooling loss. Fresh water injection to the reactor could not perform because reactor pressure remained higher than the maximum DDFP discharge head, which made the positive feedback loop F1 to the core cooling loss, as shown anti-clockwise in Figure 2. Here, high 


\section{International Journal of Engineering Applied Sciences and Technology, 2021 \\ Vol. 6, Issue 4, ISSN No. 2455-2143, Pages 68-73 \\ Published Online August 2021 in IJEAST (http://www.ijeast.com)}

reactor pressure provides the positive feedback through the delayed fresh water injection to the reactor, consequently boosting the loss of core cooling function.

The accident advanced to the core melting condition due to the core cooling loss. The confinement of the radioactive material is vital to the NPP safety as the core melting is evolved. But, the containment venting was delayed due to the complexity of the venting valves operation, and the harsh radiological condition. Finally, the venting was started by using an air compressor. So, the use of the air compressor to operate the venting valves made a negative influence on the delayed containment venting, as shown by the '-' sign in Figure 2.

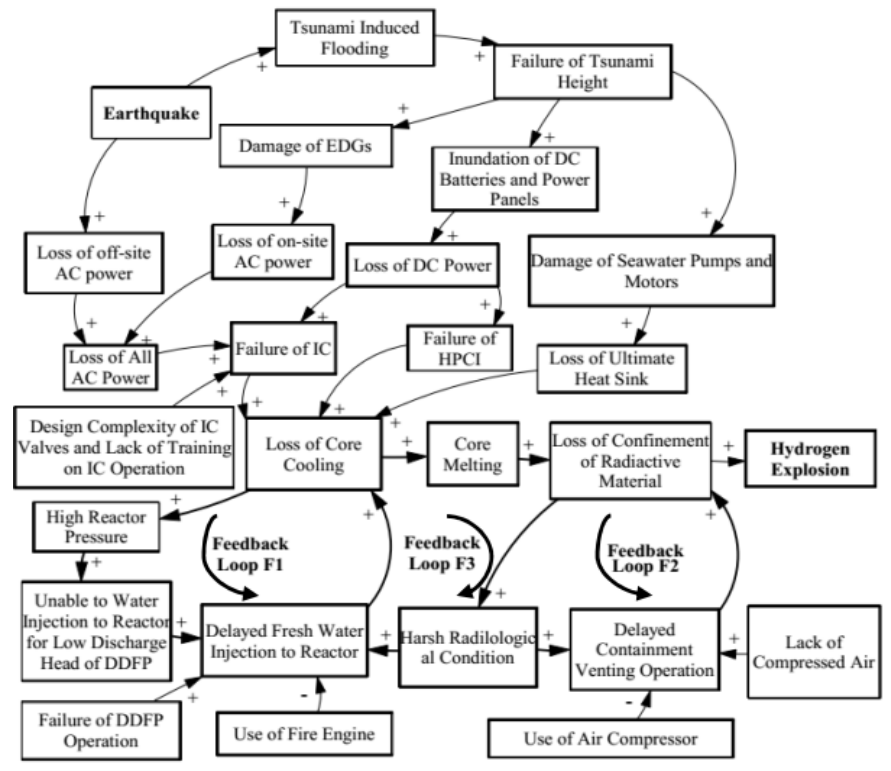

Fig. 2. System Dynamics Model for Causes of Fukushima Daiichi NPP unit-1 Accident

The unintended radioactive release from the containment presumably occurred due to the delayed venting, making harsh radiological condition, which ultimately delayed the operator actions in venting valve operation by creating the positive feedback loop F2 to the loss of confinement of the radioactive material as shown anti-clockwise in Figure 2. Here, the harsh radiological condition provides the positive feedback through the delayed venting, consequently boosting the loss of the confinement of the radioactive material.

Moreover, the harsh radiological condition originated from the loss of the confinement function, which delayed the fresh water injection to the reactor by making operator actions difficult in the field, which made the positive feedback loop F3 to the loss core cooling through the core melting to the loss of the confinement function, as shown clockwise in Figure 2. Here, the harsh radiological condition provides the positive feedback through the delayed fresh water injection to the reactor, boosting the core cooling loss, through core melting progress and the loss of the confinement of the radioactive material.

As shown in Figure 2, the major causes of Fukushima Daiichi unit-1 accident was the earthquake, tsunami induced flooding, the design failure of Tsunami height, the loss of off-site and on-site AC power, the loss of DC power, the loss of ultimate heat sink, the failure of HPCI system, the failure of IC system, the delayed fresh water injection to the reactor, and the delayed operation of the containment venting. There are also other causes which positively influence the occurrence of major causes such as the damage of the cooling seawater pumps and motors, the damage of EDGs, the inundation of the on-site DC batteries and power panels, the design complexity of isolation valves of ICs and the lack of training on IC operation, the high reactor pressure, the failure of DDFP, the harsh radiological condition, and the lacking of compressed air supply. All of these causes positively influence the failure of the basic safety function of the core cooling, and the confinement of the radioactive material, and, the severe accident with hydrogen explosion occurred. Only the fire engine and air compressor played the negative role in the accident progress according to the model, but the accident could not be avoided.

The earthquake and tsunami produced a series of causes to the occurrence of the severe accident by the dynamics of the failures of different systems and components. If the conservative design of Tsunami height, the proper protection for power sources such as water proofs rooms and the higher elevation, the diversified and redundant power supply system, the proper designing of operational mode of isolation valves of IC, and the proper training of operators on the functioning mechanism of safety systems were implemented, Fukushima Daiichi NPP unit-1 accident could be avoided.

\section{CONCLUSION}

A system dynamics model is developed by analyzing the chronological accident progression and causes of the Fukushima Daiichi NPP unit-1 accident. The cause-effect relationship and qualitative causal loop and feedback loop was applied to develop this model.

The chronological accident progression review demonstrates that the safety system of the NPP could not function properly, and the fundamental safety functions, namely core cooling and confinement of radioactive materials were lost, and the severe accident with hydrogen explosion occurred in Fukushima Daiichi NPP unit-1. Besides, the operator encountered difficulties to operate the emergency safety systems and to take appropriate actions related to the activities of AM measures during the accident.

The developed system dynamics model shows that the earthquake, the tsunami induced flooding, the design failure of Tsunami height, the loss of off-site and on-site AC power, the loss of almost all DC power, the loss of ultimate heat sink, the 


\section{International Journal of Engineering Applied Sciences and Technology, 2021 \\ Vol. 6, Issue 4, ISSN No. 2455-2143, Pages 68-73 \\ Published Online August 2021 in IJEAST (http://www.ijeast.com)}

failure of HPCI system, the failure of IC system, the design complexity of isolation valves of ICs and the lack of training on IC operation, the delayed water injection to the reactor, the delayed operation of the containment venting, the lacking of compressed air supply for valve operation, high reactor pressure, and the harsh radiological condition are the causes of the Fukushima Daiichi NPP unit-1 accident. All of these causes positively boost the severe accident occurrence while the use of the fire engine and air compressor played a negative role in the accident progress according to the model.

The foremost contribution of this study is the development of the system dynamics model and the identification of three positive feedback loops with a number of causal relations among the accident causes. Another contribution is the finding of two causes, namely, high reactor pressure and harsh radiological condition, produced during the accident, and these causes eventually boost the severe accident progression positively. The application of system dynamics modelling in NPP accidents is a novel approach. The insights of this study can be observed by visualizing the dependencies among the causes of the accident through the developed model.

The diversity, redundancy, and reliability must be considered for the designing of the safety system in the future design of NPP to ensure safety. Moreover, the conservative design to protect the power sources from natural events and the loss of all power in the NPP for an extended period of time must be considered during the design of NPP.

\section{REFERENCES}

[1] International Atomic Energy Agency (2008), TECDOC1594, Analysis of Severe Accidents in Pressurized Heavy Water Reactors, Vienna. https://wwwpub.iaea.org/MTCD/Publications/PDF/te_1594_web.pdf

[2] International Atomic Energy Agency (2016), Specific Safety Requirements, NO. SSR-2/1 (Rev. 1), Safety of Nuclear Power Plants: Design, Vienna. https://wwwpub.iaea.org/MTCD/publications/PDF/Pub1715web46541668.pdf

[3] Tokyo Electric Power Company (2012), Fukushima Nuclear Accident Analysis Report. https://www.tepco.co.jp/en/press/corpcom/release/betu12_e/images/120620e0104.pdf

[4] International Atomic Energy Agency (2015), The Fukushima Daiichi Accident, Technical Volume 1, Description and Context of the Accident, Vienna.https://wwwpub.iaea.org/MTCD/Publications/PDF/AdditionalVolume s/P1710/Pub1710-TV1-Web.pdf

[5] Mizokami S., and Kumagai Y. (2015), Event Sequence of the Fukushima Daiichi Accident, In: Ahn, J., Jensen, M., Juraku, K., Nagasaki, S. and Tanaks, S., Eds., Reflections on the Fukushima Daiichi Nuclear Accident, Springer, Cham, (pp. 21-50).

[6] Kim Sung Il, Park Jong Hwa, Ha Kwang Soon, Cho Song-Won, and Song Jin Ho (2016), Analysis of Fukushima unit 2 accident considering the operating conditions of RCIC system, Nuclear Engineering and Design, 298, (pp. 183-191).

[7] Radzicki M. J. and Taylor R. A. (1997), Introduction to System Dynamics: A Systems Approach to Understanding Complex Policy Issues. US Department of Energy.http://www.systemdynamics.org/DLIntroSysDyn/start.htm

[8] Ahmad Taher Azar (2012), System dynamics as a useful technique for complex systems, International Journal of Industrial and Systems Engineering, Vol. 10 (4), (pp. 377410).

[9] Williams,T. (2002), Modelling Complex Projects. Chichester, UK: John Wiley \& Sons, Ltd.

[10] Wang Qi-Fan, Ning Xiao, and You Jiong (2005), Advantages of System Dynamics Approach in Managing Project Risk Dynamics, Journal of Fudan University (Natural Science), 44(2).

[11] Hossen M. M., Kang K.-H., and Song J. H. (2016), Developing Off-site Emergency Preparedness and Response Model (OEPRM) for Severe Accident of NPP in a Densely Populated Country Using System Dynamics Approach, Transactions of the Korean Nuclear Society Spring Meeting, Jeju, Korea.

[12] Nöggerath Johannis, Robert J. Geller, and Viacheslav Gusiakov (2011), Fukushima: The myth of safety, the reality of geoscience, Bulletin of the Atomic Scientists 67(5), (pp. 37-46).

[13] General Electric Advanced Technology Manual, Chapter 7.1 Fukushima Dai-ichi Earthquake and Tsunami Event, USNRC HRTD, Rev 0114, (Accessed July 26, 2021) https://www.nrc.gov/docs/ML1414/ML14140A185.pdf

[14] The Saskawa Peace Foundation (2012), The Fukushima Nuclear Accident and Crisis Management, Lessons for Japan-US Alliance Cooperation, Tokyo. https://www.spf.org/en/global-data/book_fukushima.pdf

[15] Tokyo Electric Power Company (2012), Fukushima Nuclear Accidents Investigation Report, Attachment. https://www.tepco.co.jp/en/press/corpcom/release/betu12 _e/images/120620e0106.pdf.

[16] National Research Council (2014), Lessons Learned from the Fukushima Nuclear Accident for Improving Safety of U.S. Nuclear Plants. Washington, DC: The National Academies Press. https://doi.org/10.17226/18294

[17] Song Jin Ho, and Kim Tae Woon (2014), Severe Accident Issues Raised by the Fukushima Accident and Improvements Suggested, Nuclear Engineering and Technology, 46(2), (pp. 207-216). 
[18] Hirano Masashi, Yonomoto Taisuke, Ishigaki Masahiro, Watanabe Norio, Maruyama Yu, Sibamoto Yasuteru, Watanabe Tadashi, and Moriyama Kiyofumi (2012), Insights from review and analysis of the Fukushima Daiichi accident, Journal of Nuclear Science and Technology, 49(1), (pp. 1-17).

[19] Japan Meteorological Agency (2013), Lessons learned from the tsunami disaster caused by the 2011 Great East Japan Earthquake and improvements in JMA's tsunami warning

system.https://www.data.jma.go.jp/svd/eqev/data/en/tsuna $\mathrm{mi} /$ LessonsLearned_Improvements_brochure.pdf

[20] Nuclear Energy Agency (2015), Benchmark Study of the Accident at the Fukushima Daiichi Nuclear Power Plant (BSAF Project), NEA/CSNI/R(2015)18.

[21] Tokyo Electric Power Company (2015), Evaluation of the Situation of Cores and Containment Vessels of Fukushima Daiichi Nuclear Power Station Units-1 to 3 and Examination into Unsolved Issues in the Accident Progression, Tokyo. Progress Report No. 3. https://www.tepco.co.jp/en/press/corpcom/release/betu15_e/images/150520e0102.pdf

[22] Ventana Systems, Inc. (2007), Vensim, User's Guide Version http://www.cs.vsu.ru/ svv/swe/VensimUsersGuide.pdf 